\title{
The clinical importance of changes in Treg and Th17 lymphocyte subsets in splenectomized patients after spleen injury
}

\author{
Witold Zgodziński1,A-F, Ewelina Grywalska ${ }^{2, A-F}$, Dorota Siwicka-Gierobab, B,F, Agata Surdacka 2,B,F, \\ Krzysztof Zinkiewicz ${ }^{1, B, E, F}$, Dariusz Szczepanek, ${ }^{4, B, F}$, Grzegorz Wallner ${ }^{1, E, F}$, Jacek Roliński', ${ }^{2, F}$ \\ ${ }^{1} 2^{\text {nd }}$ Department of General, Gastrointestinal Surgery and Surgical Oncology of the Alimentary Tract, Medical University of Lublin, Poland \\ 2 Department of Clinical Immunology and Immunotherapy, Medical University of Lublin, Poland \\ ${ }^{3}$ Department of Anesthesiology, Medical University of Lublin, Poland \\ ${ }^{4}$ Department of Neurosurgery and Pediatric Neurosurgery, Medical University of Lublin, Poland \\ A - research concept and design; B - collection and/or assembly of data; C - data analysis and interpretation; \\ $D$ - writing the article; $E$ - critical revision of the article; $F$ - final approval of the article
}

Address for correspondence

Ewelina Grywalska

E-mail: ewelina.grywalska@gmail.com

Funding sources

This study was supported by the National Science

Center, Poland (grant Nos.: UM0-2011/01/N/

NZ6/01762 and UM0-2012/05/B/NZ6/00792).

Conflict of interest

None declared

Received on March 11, 2017

Reviewed on April 5, 2017

Accepted on May 15, 2017
Abstract

Background. Splenectomized patients are more prone to bacterial infections due to their immunocompromised status. Little is known about the role of T helper 17 (Th17) and T regulatory cells (Treg) in the immune system of patients after the removal of the spleen.

Objectives. The aim of the present study was to analyze possible changes in CD4+ lymphocyte T subsets, especially Treg and Th17, in patients who had undergone splenectomy.

Material and methods. The study included a group of 67 male patients ( $41.74 \pm 16.22$ years). All patients had undergone splenectomy because of spleen injury. Mean time elapsed from splenectomy to analysis was $9.1 \pm 4.6$ years. Control samples were obtained from 20 male healthy volunteers. The percentages and absolute counts of Th17 and Treg were measured using the flow cytometry method.

Results. The analysis of the antibody titer against 23 serotypes of Streptococcus pneumoniae (S. pneumoniae) in the splenectomized patients revealed its elevated values compared to controls ( $p=0.0016)$. Higher percentages and absolute counts of Treg cells were found in the splenectomized group vs controls $(p<0.000007)$. Lower percentages and absolute counts of the Th17 subset were found in the study group vs controls ( $p<0.000002$ and $p<0.00006$, respectively). The Treg cell percentage was positively correlated with the antibody titer against $S$. pneumoniae $(p<0.02)$. Th17 cells were reversely correlated with the antibody titer ( $p<0.004$ and $p<0.001$ for absolute counts and percentage values, respectively). The Th17 subset values were significantly lower in the splenectomized patients who reported a higher frequency of upper respiratory tract infections (URTI) ( $p<0.0001)$. No correlations were found between the time elapsed since splenectomy and the Treg or Th17 cell values in the study group.

Conclusions. Splenectomy results in an important deterioration of the Treg/Th17 cell balance with a predominance of immunoregulatory Tregs, which can contribute to insufficient immune response to infection.

Key words: immune response, T helper 17 cells, T regulatory cells, splenectomy

DOI

10.17219/acem/73734

Copyright

Copyright by Author(s)

This is an article distributed under the terms of the

Creative Commons Attribution Non-Commercial License

(http://creativecommons.org/licenses/by-nc-nd/4.0/) 


\section{Introduction}

In 1919, Morris and Bullock reported on a preliminary study indicating the importance of the spleen in resistance to infection. ${ }^{1}$ Further studies on animal models have shown significant relationships between splenectomy and the peripheral leukocyte count. ${ }^{2}$

After splenectomy, mechanisms that play important roles in bacterial clearance are impaired, which leads to an increased risk of severe infections. The absence of the phagocytic function of the spleen and the long-term impairment of humoral response to encapsulated bacteria are the main reasons for the overwhelming postsplenectomy infection (OPSI) syndrome. This severe infection occurs at an estimated incidence of $0.23-0.42 \%$ per year, with a lifetime risk of $5 \% .^{3,4}$ The course of OPSI can be lifethreatening, with a mortality rate of $38-69 \% .^{3,5,6}$ Early diagnosis and aggressive therapy can decrease the number of fatal outcomes to $10-40 \%{ }^{7}$ The highest risk of infection occurs during the first 3 years after splenectomy, particularly in children younger than 5 years. ${ }^{8,9}$ OPSI is most commonly induced by encapsulated bacteria and Streptococcus pneumoniae (S. pneumoniae) is responsible for $50-90 \%$ of all cases of OPSI. 3,7 This has been attributed to the absence of marginal zone B cells in these patients. ${ }^{10}$ Each patient should be vaccinated for S. pneumoniae both before and after splenectomy to minimize the risk of infection. According to the guidelines from the Centers for Disease Control and Prevention (CDCs), it is recommended to vaccinate for S. pneumoniae and Haemophilus influenzae type b (H. influenzae) at least 14 days before surgery, and to vaccinate for S. pneumoniae, H. influenzae and Neisseria meningitidis after splenectomy. Vaccination for influenza is also recommended once a year in this group of patients. ${ }^{11}$ In cases of urgent splenectomy, vaccination before surgery is not applicable. In these cases, it is important to follow the guidelines for vaccination after surgery. However, post-splenectomy vaccinations, especially in urgent cases, seem to be less effective. ${ }^{8}$ The lack of the spleen causes significant disorders in humoral immune response. ${ }^{12}$ Despite a significant amount of evidence on B-lymphocyte function impairment, little is known about the distribution of separate populations of T-lymphocytes in splenectomized patients. CD4+ T cells are essential for directing immune responses during host defense and for the pathogenesis of inflammatory diseases. Recently, more attention has been paid to $\mathrm{T}$ regulatory cells (Treg cells) and the positive effects they exert by regulating immune response to self-antigens. Treg cells are a subset of phenotypically and functionally specific $\mathrm{T}$ lymphocytes which play an important role in the maintenance of immune tolerance. Foxp3, a member of the forkhead/winged-helix family of the transcription factor, has been identified as the best marker of Treg cells. ${ }^{13}$ The dysfunction of Treg cells is observed in a variety of autoimmune diseases such as systemic lupus erythematosus (SLE) and rheumatoid arthritis. ${ }^{14,15} \mathrm{~T}$ helper 17 (Th17) IL-17A+CD3+CD4+ cells represent a subset of $\mathrm{T}$ helper cells that can play an active role in several inflammatory and autoimmune diseases. ${ }^{16}$ It has been demonstrated that human Th17 cells express IL-17A, IL-17F, IL-22, IL-26, IFN- $\gamma$, the chemokine CCL20, the transcription factor ROR- $\gamma \mathrm{t}$, and IL-23R. ${ }^{17}$ It has been shown that the balance of Treg/Th17 controls immune response as an important factor in regulating the Th cell function relating to the Th1/Th2 shift in the graft vs host disease. ${ }^{18}$ The Treg/Th17 imbalance contributes to the development of autoimmune diseases, such as SLE, ${ }^{19}$ primary nephrotic syndrome ${ }^{20}$ and idiopathic thrombocytopenic purpura. ${ }^{21}$

The aim of the present study was to analyze possible changes in the CD4+ lymphocyte $\mathrm{T}$ subsets, especially Treg and Th17, in patients who had undergone splenectomy, and to assess the relationships between increased susceptibility to infections and the Treg/Th17 status in this group.

\section{Material and methods}

\section{Study and control groups}

Between 2012 and 2013, a group of 67 male patients, with an average age of $41.74 \pm 16.22$ years, was recruited. All patients enrolled were splenectomized because of an abdominal trauma with spleen injury. Mean time elapsed from splenectomy to analysis was $9.1 \pm 4.6$ years. Control samples of peripheral blood were obtained from 20 healthy male volunteers (aged $42.95 \pm 15.3$ years). None of the patients or controls had been receiving drugs affecting the immune system; none showed any signs of infection (within the last 2 months before the study) or any signs of autoimmune or allergic diseases, and none had received blood transfusions. None had been receiving immunosuppressive or immunomodulative treatment within the previous 3 months. To avoid hormonal changes during menstrual cycles, only male patients and controls were enrolled for the study. Fifty-nine patients (88.05\%) reported more frequent upper respiratory tract infections (URTI) after splenectomy (4 or more cases of infection treated with antibiotics per year) and 8 patients (11.94\%) did not observe any change in the prevalence of URTI. The peripheral blood (PB) samples were drawn from the basilic vein for the following tests: 1 . serum specific pneumococcal antibody titers before vaccination $(3 \mathrm{~mL}$ of peripheral blood collected to tubes with a clotting activator); 2 . frequencies of selected lymphocyte subsets $(5 \mathrm{~mL}$ of peripheral blood collected to tubes with the anticoagulant ethylenediaminetetraacetic acid - EDTA). Serum samples were stored at $-70^{\circ} \mathrm{C}$ until the time of specific pneumococcal antibody titer analysis. The percentages of lymphocyte subsets were assessed on fresh peripheral blood samples from patients and healthy volunteers. This study was carried out 
in accordance with the Code of Ethics of the World Medical Association (Declaration of Helsinki) for experiments involving humans. The Local Ethics Committee approved the research and patients gave their prior written consent.

\section{The isolation of peripheral blood mononuclear cells and the detection of Th17 and Treg cells}

The isolation of peripheral blood mononuclear cells (PBMCs) and the detection of Th17 and Treg cells were performed as described previously. ${ }^{22}$

The peripheral blood was diluted $1: 1$ with a $0.9 \%$ phosphate-buffered saline (PBS) without calcium $\left(\mathrm{Ca}^{2+}\right)$ or magnesium $\left(\mathrm{Mg}^{2+}\right)$ ions (Biochrome AG, Berlin, Germany). The diluted material was then overlaid on $3 \mathrm{~mL}$ of Gradisol L preparation (Aqua Medic, Łódź, Poland) with a specific gravity of $1.077 \mathrm{~g} / \mathrm{mL}$ and subjected to density gradient centrifugation at $700 \times \mathrm{g}$ for $20 \mathrm{~min}$. The obtained fraction of PBMCs was collected with a Pasteur pipette and washed twice in PBS without $\mathrm{Ca}^{2+}$ and $\mathrm{Mg}^{2+}$ ions for $5 \mathrm{~min}$. Next, the cells were suspended in $1 \mathrm{~mL}$ of PBS without $\mathrm{Ca}^{2+}$ and $\mathrm{Mg}^{2+}$, and counted in the Neubauer chamber, and their viability was determined by a trypan blue dye exclusion assay (0.4\% Trypan Blue Solution; Sigma-Aldrich, St. Louis, USA).

For the detection of Th17 cells, PBMCs were resuspended in RPMI-1640 culture medium (Sigma-Aldrich) containing $10 \%$ heat-inactivated fetal calf serum (FCS, Sigma-Aldrich), $2 \mathrm{mM}$ l-glutamine, $100 \mathrm{U} / \mathrm{mL}$ penicillin (Sigma-Aldrich), and $100 \mu \mathrm{g} / \mathrm{mL}$ streptomycin (Sigma-Aldrich). Mononuclear cells were stimulated for $5 \mathrm{~h}$ at $37^{\circ} \mathrm{C}$ in $5 \% \mathrm{CO}_{2}$ with $25 \mathrm{ng} / \mathrm{mL}$ of phorbol 12-myristate 13-acetate (PMA, Sigma Chemical, St. Louis, USA) and $1 \mu \mathrm{g} / \mathrm{mL}$ of ionomycin (Sigma Aldrich) in the presence of $10 \mu \mathrm{g} / \mathrm{mL}$ of brefeldin A (Sigma-Aldrich), which blocks the intracellular transport processes resulting in the accumulation of cytokine proteins on the Golgi complex. Next, PBMCs were collected, washed with PBS solution and prepared at a final concentration of 106 cells/mL. The number of viable leukocytes was determined using a $1 \%$ trypan blue dye exclusion assay. Later, the mononuclear cells were stained with anti-CD3 CyChrome and anti-CD4 fluorescein-isothiocyanate (FITC) conjugated monoclonal antibodies (Becton Dickinson, San Diego, USA). The permeabilization of cell membranes was achieved with a Cytofix/Cytoperm Kit (BD Pharmingen, San Jose, USA), which was added for $15 \mathrm{~min}$ at a temperature of $4^{\circ} \mathrm{C}$. Next, the cells were washed twice with PBS. The permeabilized cells were stained with a phycoerythrin (PE)-conjugated anti-human IL-17A monoclonal antibody (eBioscience, San Diego, USA). Then, cells were washed twice with PBS again.

For the detection of Treg CD4+CD25+Foxp3+ cells, the cell surface and intracellular antigens were determined on fresh cells at the time of sample submission by cell staining according to the manufacturer's protocols. A total of $500 \mu \mathrm{L}$ of cell suspensions were added to $5 \mu \mathrm{L}$ of an appropriate solution of anti-human CD25 PE and anti-human CD4 PE-Cy5-conjugated antibodies (BioLegend, San Diego, USA). Next, the mixture of cells and antibodies was incubated for $30 \mathrm{~min}$ at $4^{\circ} \mathrm{C}$ in the dark, centrifuged, washed twice by adding $1 \mathrm{~mL}$ of cold PBS to each tube with $1 \%$ sodium azide and $1 \%$ FCS, and centrifuged again at $400 \times \mathrm{g}$ for $10 \mathrm{~min}$. After the standard incubation with antibodies directed against surface markers, the incubation by fixation and permeabilization with FoxP3 Fix/Perm Buffer and FoxP3 Perm Buffer (BioLegend) was performed. Then, the incubation with antibodies directed against the intracellular protein FoxP3 - anti-human FoxP3 (Pacific Blue) monoclonal antibody (BioLegend) was carried out. Later, the supernatant was separated and, after washing, each sample was suspended in $200 \mu \mathrm{L}$ of PBS.

The cells were immediately analyzed with a Becton Dickinson Canto II flow cytometer and analyzed by using FACSDiva ${ }^{\mathrm{TM}}$ software (Becton Dickinson). The results were presented as the percentage of CD45+ cells stained with the antibody. The percentage of positive cells was calculated via a comparison with the control. Background fluorescence was determined using isotype-matched, directly conjugated mouse anti IgG1/IgG2 $\alpha$ monoclonal antibodies. The samples were gated on forward scatter vs side scatter to exclude debris and cell aggregates. ${ }^{22}$ An example of a cytometric analysis is presented in Fig. 1.

\section{The assessment of basic lymphocyte subsets}

Three-color immunofluorescence analyzes were performed using a FACS Calibur flow cytometer (Becton Dickinson) equipped with a $488 \mathrm{~nm}$ argon laser. A minimum of 10,000 events were acquired and analyzed using CellQuest software (Becton Dickinson). The percentage of cells expressing surface markers was analyzed. The cells were phenotypically characterized by incubation (20 min in the dark at room temperature) with a combination of relevant FITC- PE- and CyChrome-labeled monoclonal antibodies. Immunofluorescence studies were performed using a combination of the following mAbs: CD3 FITC/CD19 PE and CD8 FITC/CD4 PE (Becton Dickinson). ${ }^{23}$

\section{Serum pneumococcal antibody}

\section{assessment}

The serum pneumococcal antibody assessment was performed on all subjects. The amount of anti-capsular polysaccharide antibody specific to 23 pneumococcal serotypes $(1,2,3,4,5,6 \mathrm{~B}, 7 \mathrm{~F}, 8,9 \mathrm{~N}, 9 \mathrm{~V}, 10 \mathrm{~A}, 11 \mathrm{~A}, 12 \mathrm{~F}, 14$, 15B, 17F, 18C, 19A, 19F, 20, 22F, 23F, 33F) was determined using a commercial ELISA test (ELIZEN Pneumococcus IgG Assay; Zentech, Liege, Belgium). Each of the serum samples was pre-adsorbed with $10 \mu \mathrm{g} / \mathrm{mL}$ polysaccharide $\mathrm{C}$ (C-PS; Statens Serum Institut, Copenhagen, Denmark) for $1 \mathrm{~h}$ at $37^{\circ} \mathrm{C}$ before quantification to increase the specificity 


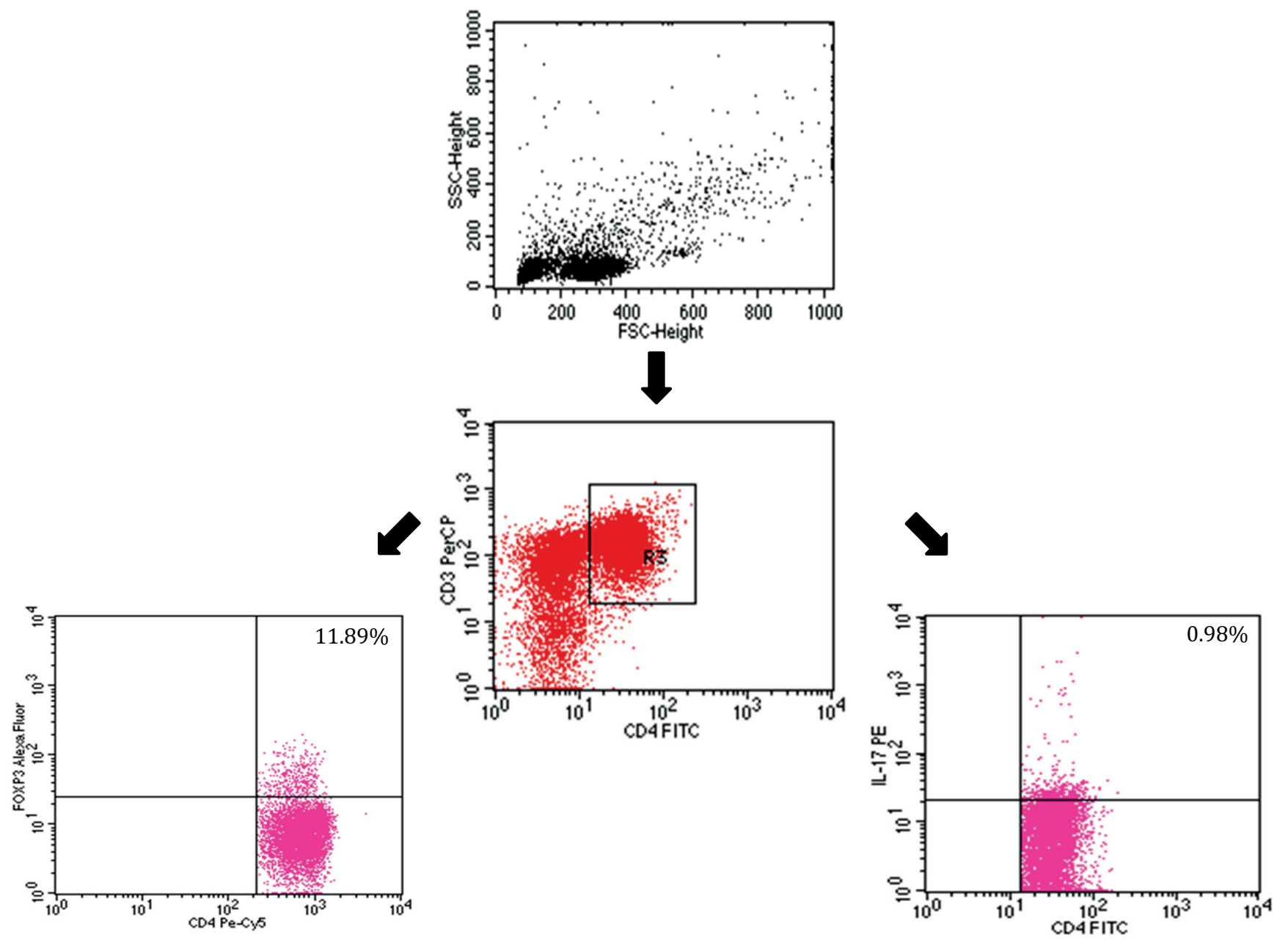

Fig. 1. An example of a 3-color flow cytometry analysis of lymphocytes from a splenectomized patient

The upper dot-plot shows the forward scatter/side scatter (FSC/SSC) distribution and the gate used to select lymphocytes for analysis. The lower left flow cytometry dot-plot shows the analysis of the percentage of Treg cells; the analysis was based on gating a subpopulation of FoxP3-positive Treg cells among TCD4-positive lymphocytes. The lower right flow cytometry dot-plot shows the analysis of the percentage of Th17 cells; the analysis was based on gating a subpopulation of Th17 cells among T CD4-positive lymphocytes. The number in the upper right quadrant in the dot-plots represents the percentage of Treg cells (bottom left dot-plot) and the percentage of Th17 cells (bottom right dot-plot).

of the test. The evaluation procedure was followed according to the manufacturer's instructions and an automatic VICTOR3 reader (Perkin Elmer, San Diego, USA) was used for result interpretation. ${ }^{24}$

\section{Statistical analysis}

The normal distribution of continuous variables was verified with the Shapiro-Wilk test. Categorical variables were presented as percentages and were compared using the $\chi^{2}$ test. Continuous variables were presented as means and standard deviations (SD). The U Mann-Whitney test and the Student's t-test were applied for intergroup comparisons of the variables, according to the distribution. Pearson's linear correlation coefficient $(r)$ was calculated to disclose relationships between the variables. All calculations were conducted using STATISTICA v. 10 software (StatSoft, Tulsa, USA). A p-value $<0.05$ was considered statistically significant.

\section{Results}

The analysis of the blood samples taken from the splenectomized patients revealed elevated antibody titer against $S$. pneumoniae compared to the healthy control group (833.68 \pm 535.98 vs $284.6 \pm 182.02 ; \mathrm{p}=0.0016)$ (Fig. 2 ). In the study group, a lower percentage of CD4+ cells was noted compared to the controls (median $37.89 \%$ vs $44.43 \%$; $<$ 0.00128) and a higher percentage and quantity of CD19+ cells compared to the controls (median $11.6 \%$ vs $8.79 \%, \mathrm{p}<0.00001$ and mean $0.328 \pm 0.156$ vs $0.274 \pm 0.241$, $\mathrm{p}<0.006$, respectively). In the Treg subset, a significantly higher percentage (median 9.85\%) and total amount (mean $0.285 \times 10^{3} / \mathrm{mm}^{3} \pm 0.133$ ) were noted in the study group vs controls (5.22\%, $\mathrm{p}<0.000001$ and $0.128 \times 10^{3} / \mathrm{mm}^{3} \pm 0.057$, $\mathrm{p}<0.000007$, respectively) (Fig. 3 ). In the Th17 subset, a significantly lower percentage (median $0.85 \%$ ) and total amount (mean $0.027 \times 10^{3} / \mathrm{mm}^{3} \pm 0.021$ ) were found in the study group vs controls $(2.64 \%, \mathrm{p}<0.000002$ and 


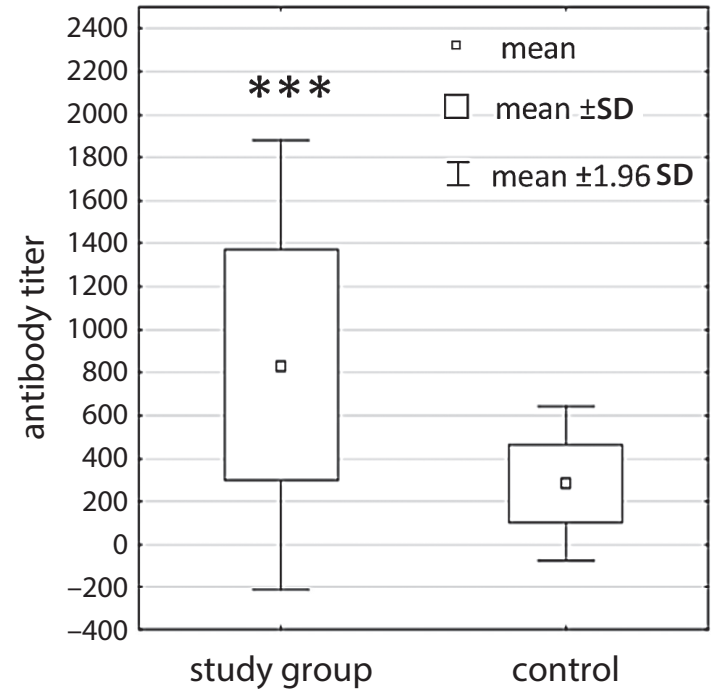

Fig. 2. The difference in antibody titer between splenectomized patients (study group) and controls

*** $p=0.0016$

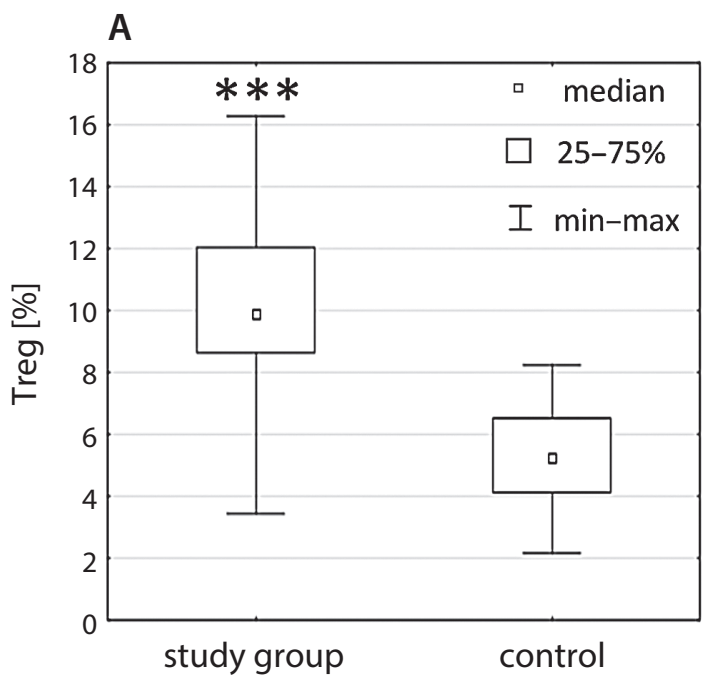

$0.072 \times 10^{3} / \mathrm{mm}^{3} \pm 0.058, \mathrm{p}<0.00006$, respectively) (Fig. 4). Mean percentage values and mean quantity values of lymphocyte subsets in the study (splenectomized) population and the control group are presented in Table 1.

In the study group, the Treg cell percentage was positively correlated with antibody titer $(\mathrm{r}=0.467595, \mathrm{p}<0.02)$ (Fig. 5A). Conversely, there was a negative correlation between Th17 cells and antibody titer $(\mathrm{r}=-0.628008, \mathrm{p}<0.001$ and $\mathrm{r}=-0.580325, \mathrm{p}<0.004$ for percentage and total quantity values, respectively) (Fig. 5 B,C).

In the study group, among patients who reported a higher incidence of URTI, in the Th17 subset, the quantity (mean $0.019 \times 10^{3} / \mathrm{mm}^{3} \pm 0.0099$ ) and percentage values (median $0.69 \%$ ) were significantly lower compared to those of the patients who did not report a higher URTI frequency $\left(0.064 \times 10^{3} / \mathrm{mm}^{3} \pm 0.021, \mathrm{p}<0.000001\right.$ and $1.81 \%, \mathrm{p}<0.00005$, respectively) (Fig. 6). The patients with a higher incidence of URTI also had a significantly higher

Fig. 3. The differences in the percentage of the Treg subset between splenectomized patients (study group) and controls (*** $\mathrm{p}<0.000001)(\mathrm{A})$; the differences in the total amount of the Treg subset between splenectomized patients (study group) and controls $\left.{ }^{* * *} p<0.000007\right)(B)$

A

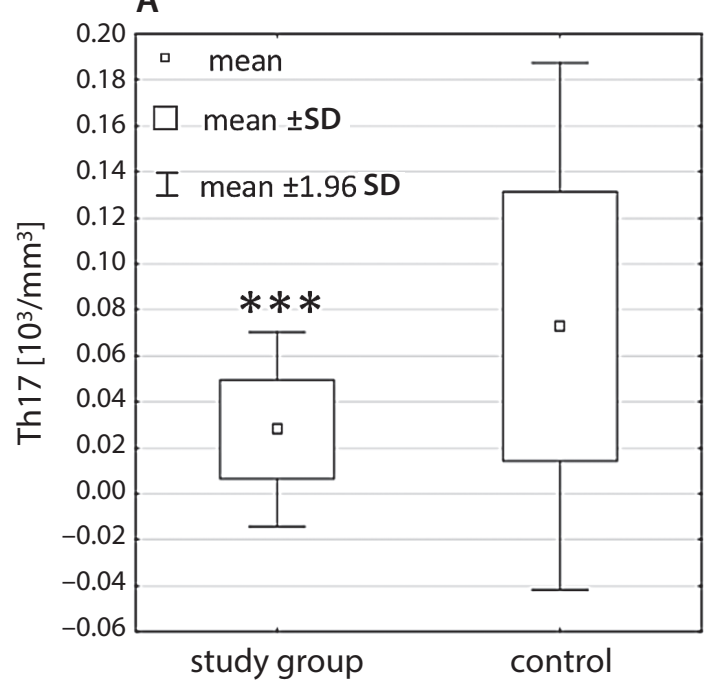

B

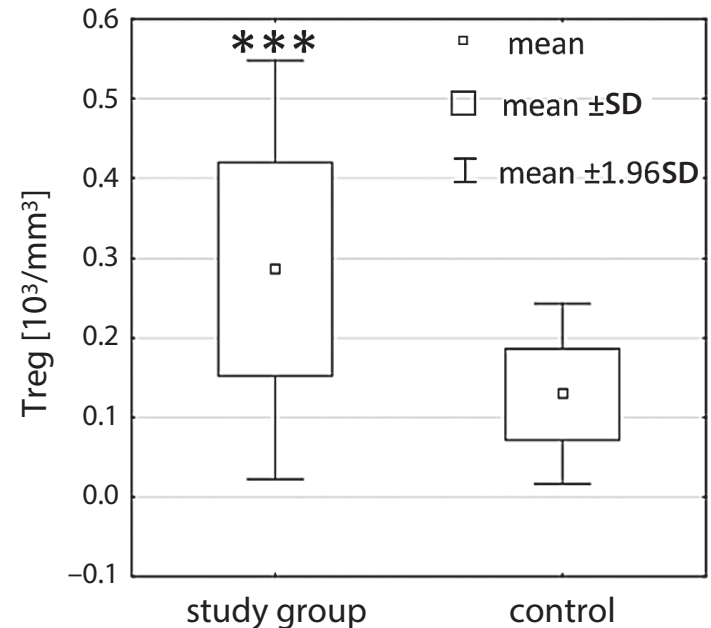

study group
B

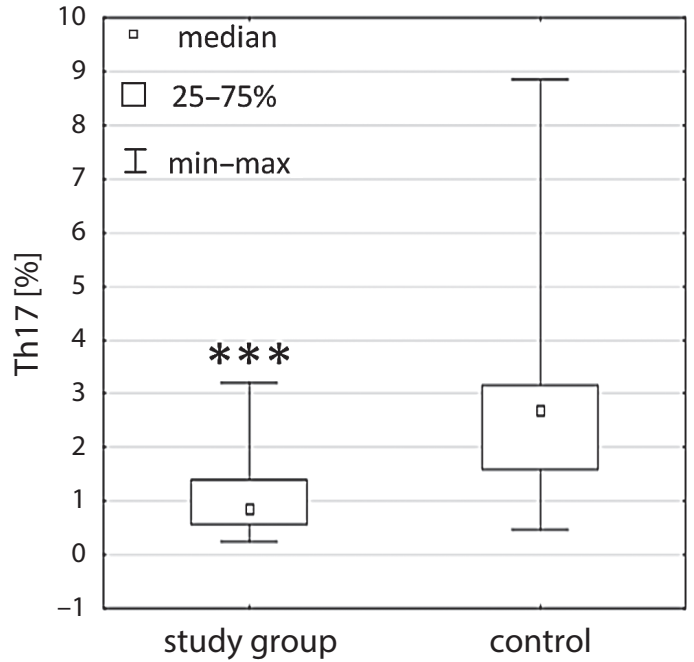

Fig. 4. The differences in the total amount of the Th17 subset between splenectomized patients (study group) and controls. $\left(^{* *} p<0.00006\right)(A)$; the differences in the percentage of the Th17 subset between splenectomized patients (study group) and controls (*** $p<0.000002$ ) 

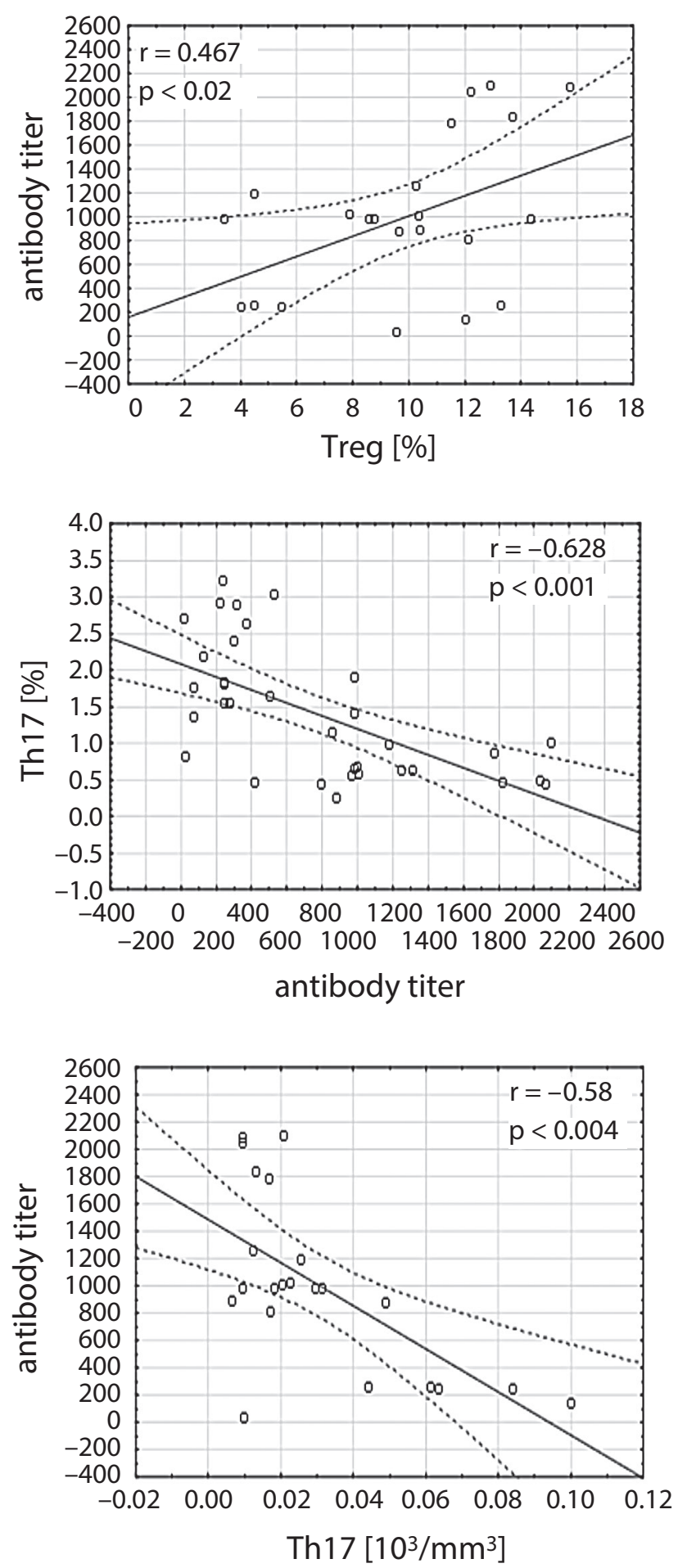

Fig. 5. Scatter diagrams presenting the positive correlation between the percentage of Treg cells and antibody titer against S. pneumoniae in splenectomized patients (A); the negative correlation between the percentage of Th17 cells (B), the quantity of Th17 cells (C) and antibody titer against $S$. pneumoniae in splenectomized patients

antibody titer ( $955.94 \pm 514.13$ vs $235.85 \pm 49.94 ; \mathrm{p}<0.0007$ ) (Fig. 7). No statistically significant correlation was found between the time elapsed since splenectomy and the Treg or Th17 cell values in the study group.

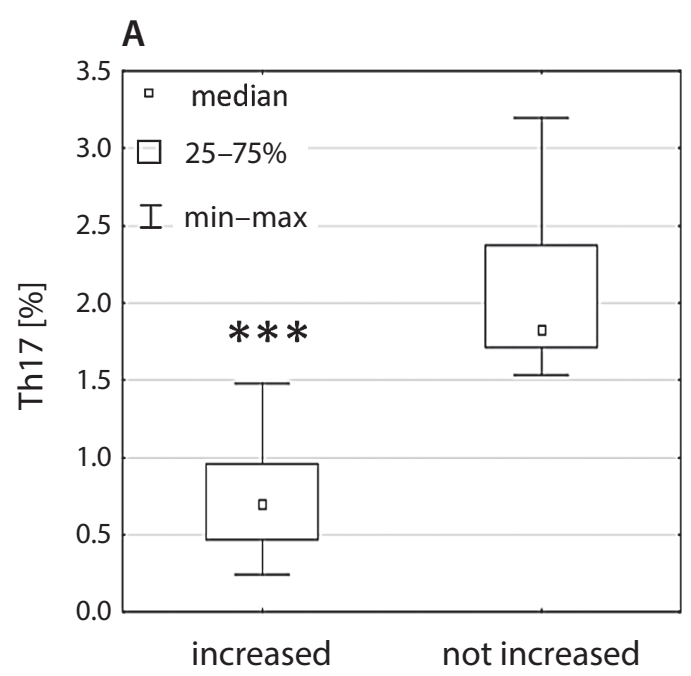

frequency of URTI after splenectomy

B

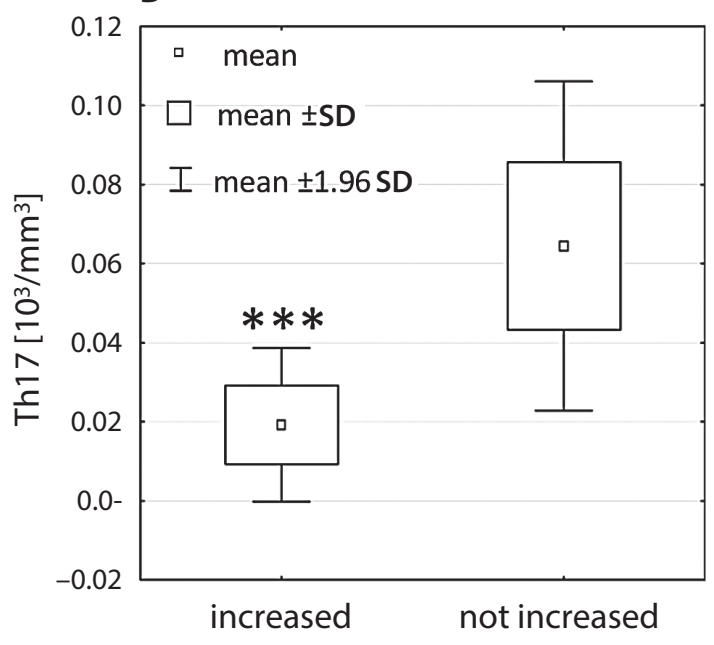

frequency of URTI after splenectomy

Fig. 6. The difference in the Th17 subset values - percentage $\left.{ }^{* * *} p<0.00005\right)(A)$ and quantity (*** $\left.p<0.000001\right)(B)-$ between splenectomized patients who reported a higher incidence of upper respiratory tract infections (URTI) and those who did not report a higher URTI frequency

\section{Discussion}

The aim of the present study was to assess the relationship between the lack of the spleen and the quantity of separate subpopulations of $\mathrm{T}$ lymphocytes as well as the number of specific antibodies against S. pneumoniae. Our study facilitates an understanding of the mechanisms which are behind weakened immune response in patients after splenectomy. The higher levels of specific antibodies against S. pneumoniae and values of CD19+ cells in the splenectomized patients compared to the control group suggest an increased exposure to antigens in bacterial capsules. It can be assumed that these patients reveal a higher exposure to bacterial antigens; thus, they are more susceptible to infections induced by this pathogen. This is in accordance with the results of previous studies indicating higher morbidity 
Table 1. Mean percentage and quantity values of lymphocyte subsets in the study population (splenectomized) and healthy control group

\begin{tabular}{|c|c|c|c|c|c|}
\hline \multirow{2}{*}{ Lymphocyte subsets } & \multicolumn{2}{|c|}{$\begin{array}{l}\text { Study group } \\
\qquad n=67\end{array}$} & \multicolumn{2}{|c|}{$\begin{array}{c}\text { Control group } \\
n=20\end{array}$} & \multirow{2}{*}{$\mathrm{p}$-value } \\
\hline & mean & standard deviation & mean & standard deviation & \\
\hline T CD3+ [\%] & 66.18727 & 8.482736 & 65.74850 & 13.25141 & n.s. \\
\hline $\mathrm{TCD} 3+\left[10^{3} / \mathrm{mm}^{3}\right]$ & 1.70540 & 0.610206 & 1.60591 & 0.52374 & n.s. \\
\hline B CD19+ [\%] & 12.74493 & 3.589680 & 11.33450 & 8.94963 & 0.00001 \\
\hline B CD19+ $\left[10^{3} / \mathrm{mm}^{3}\right]$ & 0.32872 & 0.156565 & 0.27496 & 0.24151 & 0.006 \\
\hline T CD4+ [\%] & 37.05227 & 9.676037 & 44.04050 & 3.40697 & 0.00128 \\
\hline $\mathrm{T} C D 4+\left[10^{3} / \mathrm{mm}^{3}\right]$ & 0.93664 & 0.360878 & 1.07664 & 0.27880 & n.s. \\
\hline Treg [\%] & 9.817632 & 3.006509 & 5.230500 & 1.692536 & 0.000001 \\
\hline Treg $\left[10^{3} / \mathrm{mm}^{3}\right]$ & 0.285388 & 0.133895 & 0.128761 & 0.057754 & 0.00026 \\
\hline Th17 [\%] & 1.018684 & 0.656494 & 2.833500 & 1.836078 & 0.000001 \\
\hline Th17 [103/mm $\left.\mathrm{mm}^{3}\right]$ & 0.027888 & 0.021533 & 0.072838 & 0.058360 & 0.00006 \\
\hline T CD8+ [\%] & 26.08621 & 9.130860 & 30.43050 & 7.18799 & n.s. \\
\hline $\mathrm{T} C \mathrm{CD} 8+\left[10^{3} / \mathrm{mm}^{3}\right]$ & 0.68469 & 0.381220 & 0.73060 & 0.21428 & n.s. \\
\hline
\end{tabular}

n.s. - non-significant.

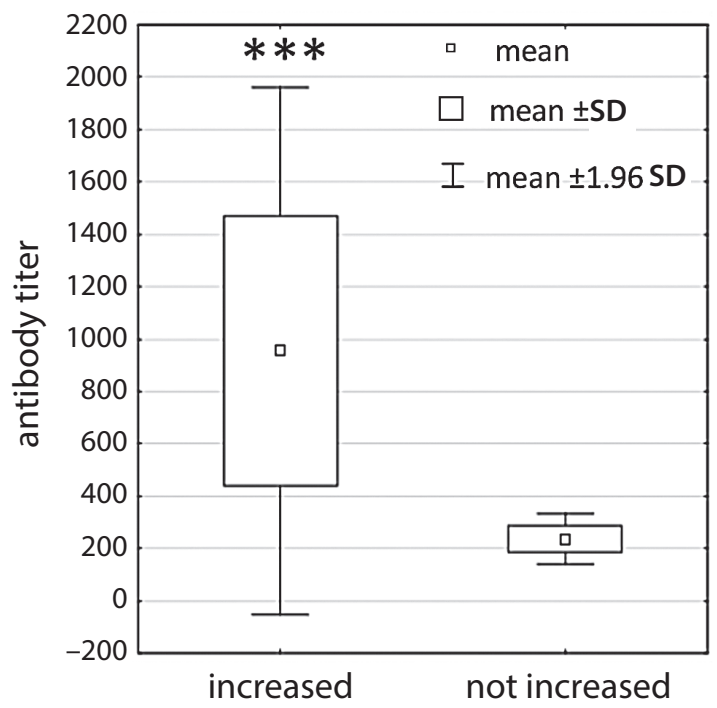

frequency of URTI after splenectomy

Fig. 7. The difference in antibody titer against S. pneumoniae between splenectomized patients who reported a higher incidence of upper respiratory tract infections (URTI) and those who did not report a higher URTI frequency $\left({ }^{* *} p<0.0007\right)$

in splenectomized patients for S. pneumoniae-related infections. ${ }^{7}$ In unvaccinated patients, the increase in the percentage of Treg lymphocytes, which also correlates with high levels of specific antibodies, seems to be distressing. The association with low levels of pro-inflammatory Th17 lymphocytes and higher antibody titer in splenectomized patients suggests that inflammatory response to $S$. pneumoniae capsule antigens is suppressed, and thus ineffective in this group. ${ }^{25,26}$ In healthy, immunocompetent patients, the preservation of an appropriate balance between Th17 and Treg cells is one of the conditions for the best inflammatory response. There is a search for the reasons of the disruption of this balance to the benefit of Th17 lymphocytes, as this is one of the causes of autoimmune diseases or chronic inflammatory disorders. ${ }^{27}$ The prevalence of regulatory T-lymphocytes is associated with immunosuppression, which results from their natural role in the immunotolerance of the body. ${ }^{28}$ Therefore, the balance between regulatory T-lymphocytes and Th17 lymphocytes plays a significant role in the development of an effective inflammatory response. ${ }^{27}$ Changes observed in this relation in patients after splenectomy may suggest that inflammatory response to the antigens contained in the $S$. pneumoniae capsula is suppressed, and thus ineffective. Therefore, despite the evidence of antigen stimulation, there is no effective immunological response from the immune system. These conclusions seem to be confirmed by the results of the quantity and percentage assessment of Th17 cells in the group of splenectomized patients reporting a higher incidence of URTI. Previous observations have demonstrated a positive correlation between the time elapsed since splenectomy and the percentage of peripheral blood CD4+ cells in the group of patients splenectomized because of an abdominal trauma. ${ }^{23}$ Findings observed in the present study show that CD4+ cells comprise a smaller subset of lymphocytes compared to controls, but there is a tendency to rebuild this population over time. In the present research, we only enrolled patients splenectomized due to spleen injury. Elective splenectomy is generally performed on patients with idiopathic thrombocytopenic purpura; however, these patients are referred to pre-surgery vaccination that may influence the status of lymphocyte subsets. This study group is homogenous and vaccinationnaive, and the results are free of any possible impact from the vaccine. Future studies are needed to assess the possible effects of vaccination on CD4+ cell frequency in splenectomized patients. 


\section{Conclusions}

This research shows for the first time that substantial changes are occurring in the immunological system after splenectomy. Splenectomy has a significant effect on the quantitative distribution of lymphocyte subsets. Patients who undergo splenectomy reveal a strong reverse balance between Treg and Th17 lymphocytes. Certainly, this is one of the factors leading to a deterioration in the immunity response of the body against bacterial antigens. The high level of specific antibodies in these patients does not correlate with effective immunity.

\section{References}

1. Morris DH, Bullock FD. The importance of the spleen in resistance to infection. Ann Surg. 1919;70:513-521.

2. Bessler H, Bergman M, Salman H, Beilin B, Djaldetti M. The relationship between partial splenectomy and peripheral leukocyte count. J Surg Res. 2004;122:49-53.

3. Davidson RN, Wall RA. Prevention and management of infections in patients without a spleen. Clin Microbiol Infect. 2001;7:657-660.

4. Shatz DV. Vaccination practices among North American trauma surgeons in splenectomy for trauma. J Trauma. 2002;53:950-956.

5. Aguilar RB, Keister KJ, Russell AC. Prevention of sepsis after splenectomy. Dimens Crit Care Nurs. 2010;29:65-68.

6. Di Sabatino A, Carsetti R, Corazza GR. Post-splenectomy and hyposplenic states. Lancet. 2011;378:86-97.

7. Morgan TL, Tomich EB. Overwhelming post-splenectomy infection (OPSI): A case report and review of the literature. J Emerg Med. 2012; 43:758-763.

8. Davies JM, Lewis MP, Wimperis J, Rafi I, Ladhani S, Bolton-Maggs PH. Review of guidelines for the prevention and treatment of infection in patients with an absent or dysfunctional spleen, prepared on behalf of the British Committee for Standards in Haematology by a working party of the Haemato-Oncology task force. $\mathrm{Br} \mathrm{J} \mathrm{Hae-}$ matol. 2011;155:308-317.

9. Evans DI. Postsplenectomy sepsis 10 years or more after operation. J Clin Pathol. 1985;38:309-311.

10. Torres A, Bonanni P, Hryniewicz W, Moutschen M, Reinert RR Welte T. Pneumococcal vaccination: What have we learnt so far and what can we expect in the future? Eur J Clin Microbiol Infect Dis. 2015;34:19-31.

11. Centers for Disease Control and Prevention (CDC). Recommended Adult Immunization Schedule - United States, 2016. www.cdc.gov/ vaccines/schedules/downloads/adult/adult-schedule.pdf. Accessed February 25, 2016
12. Zandvoort A, Timens $W$. The dual function of the splenic marginal zone: Essential for initiation of anti-TI-2 responses but also vital in the general first-line defense against blood-borne antigens. Clin Exp Immunol. 2002;130:4-11.

13. Adeegbe D, Matsutani T, Yang J, Altman NH, Malek TR. CD4(+) CD25(+) Foxp3(+) T regulatory cells with limited TCR diversity in control of autoimmunity. J Immunol. 2010;184:56-66.

14. Bonelli M, Savitskaya A, von Dalwigk K, et al. Quantitative and qualitative deficiencies of regulatory $T$ cells in patients with systemic lupus erythematosus (SLE). Int Immunol. 2008;20:861-868.

15. Sempere-Ortells JM, Perez-Garcia V, Marin-Alberca G, et al. Quantification and phenotype of regulatory $T$ cells in rheumatoid arthritis according to disease activity score-28. Autoimmunity. 2009;42:636-645.

16. Annunziato F, Cosmi L, Santarlasci V, et al. Phenotypic and functional features of human Th17 cells. J Exp Med. 2007;204:1849-1861.

17. Wilson NJ, Boniface K, Chan JR, et al. Development, cytokine profile and function of human interleukin 17-producing helper T cells. Nat Immunol. 2007;8:950-957.

18. Afzali B, Lombardi G, Lechler RI, et al. The role of T helper 17 (Th17) and regulatory $T$ cells (Treg) in human organ transplantation and autoimmune disease. Clin Exp Immunol. 2007;148:32-46.

19. Yang J, Chu Y, Yang X, et al. Th17 and natural Treg cell population dynamics in systemic lupus erythematosus. Arthritis Rheum. 2009;60: 1472-1483.

20. Shao XS, Yang XQ, Zhao XD, et al. The prevalence of Th17 cells and FOXP3 regulate T cells (Treg) in children with primary nephrotic syndrome. Ped Nephrol. 2009:24:1683-1690.

21. Yu S, Liu C, Li L, et al. Inactivation of Notch signaling reverses the Th17/Treg imbalance in cells from patients with immune thrombocytopenia. Lab Invest. 2015;95:157-167.

22. Klatka M, Grywalska E, Partyka M, Charytanowicz M, Kiszczak-Bochynska E, Rolinski J. Th17 and Treg cells in adolescents with Graves' disease: Impact of treatment with methimazole on these cell subsets. Autoimmunity. 2014:47:201-211.

23. Grywalska E, Surdacka A, Miturski A, et al. Characterisation of lymphocyte subsets in asplenic patients: Preliminary report. Centr Eur J Immunol. 2010;35:239-244.

24. Pasiarski M, Rolinski J, Grywalska E, et al. Antibody and plasmablast response to 13-valent pneumococcal conjugate vaccine in chronic lymphocytic leukemia patients: Preliminary report. PLoS One. 2014;9: e114966.

25. Josefowicz SZ, Lu LF, Rudensky AY. Regulatory T cells: Mechanisms of differentiation and function. Annu Rev Immunol. 2012;30:531-564.

26. Bettelli E, Carrier Y, Gao W, et al. Reciprocal developmental pathways for the generation of pathogenic effector $\mathrm{TH} 17$ and regulatory T cells. Nature. 2006;441:235-238.

27. Noack M, Miossec P. Th17 and regulatory T cell balance in autoimmune and inflammatory diseases. Autoimmun Rev. 2014;13:668-677.

28. Sakaguchi S. Naturally arising CD4+ regulatory T cells for immunologic self-tolerance and negative control of immune responses. Annu Rev Immunol. 2004;22:531-562. 